\title{
Concepções de professores da Academia de Polícia Militar de Brasília acerca de seus alunos
}

Daniele Alcântara Nascimento'

Teresa Cristina Siqueira Cerqueira"

\section{Resumo}

0 presente estudo refere-se a uma pesquisa exploratória de cunho qualitativo que visa a conhecer e analisar as concepções de professores civis e professores policiais militares acerca do aluno policial militar na Academia de Polícia Militar de Brasília (APMB). Foram realizadas entrevistas individuais semiestruturadas com 17 professores. Por meio da análise de conteúdo das entrevistas, identificaram-se categorias temáticas para melhor compreensão dos dados. As categorias fizeram referência, durante a discussão apresentada, à imagem do aluno policial militar, ao relacionamento interpessoal na Academia, à consciência do sistema disciplinar, ao modo como ocorre o ensino na Polícia Militar do Distrito Federal (PMDF) e ao vínculo que o aluno estabelece com a prática policial militar. Os resultados apontaram que, na concepção de professores da APMB, o aluno policial militar é alguém disciplinado, interessado em aprender e educado. Os professores afirmam ter um relacionamento positivo com o aluno e que o mesmo participa das aulas. A hierarquia estabelece-se em sala no contato professor-aluno, havendo uma consciência do sistema disciplinar e das possíveis punições advindas de transgressões. Conclui-se que as concepções de professores se formam relacionadas às crenças, valores e imagens da PMDF, abrindo caminho para que os docentes compreendam como lidam com o aluno policial militar em formação. A pesquisa revela que os professores, sejam civis ou militares, têm ciência dos limites impostos ao aluno policial militar diante de uma formação baseada na hierarquia e disciplina.

\section{Palavras-chave}

Concepções de professores - Aluno policial militar - Professor da Academia de Polícia Militar de Brasília - Polícia Militar do Distrito Federal.

I- Instituto Superior de Ciências Policiais,

Brasilia, DF, Brasil.

Contato: alcantara.daniele@gmail.com

II- Universidade de Brasília, Brasília, DF, Brasil.

Contato: teresacristinasc@gmail.com 


\section{The conceptions by Military Police Academy professors of their students}

Daniele Alcântara Nascimento'

Teresa Cristina Siqueira Cerqueira"

\section{Abstract}

This study is about an exploratory study of qualitative nature whose purpose is to get to know and analyze the concepts that both civilian and military professors hold in regard of students preparing to become policemen in the Military Police Academy of Brasilia (APMB). Individual semi-structured interviews were conducted with 17 professors. By analyzing the contents of the interviews, topics (categories) were identified for a better understanding of data. Categories were referred, during the discussion presented, to the image of the military policeman student, to the interpersonal relationship in the Academy, to the awareness of the disciplinary system, to the way teaching is conducted at the Military Police of the Federal District (PMDF) and to the link that the student builds with the military police practice. Results pointed that, in the concept of APMB professors, the military policeman student is someone disciplined, interested in learning and polite. Professors said they have a satisfactory relationship with students and that they are participative in class. The hierarchy becomes clear in the classroom through the professor-student contact, and there is an awareness of the disciplinary system and penalties that may occur in case of offense. Conclusion was that the concepts of professors are formed in relation to the beliefs, values, and images of PMDF, making way so that professors understand how to deal with the military policeman student under training. The research reveals that professors, both civilian and military, are aware of the limits imposed to the military policeman student in the perspective of an education based on hierarchy and discipline.

\section{Keywords}

Concepts of professors - Military policeman student - Professor of the Military Police Academy of Brasilia - Military Police of the Federal District.

I- Instituto Superior de Ciências Policiais,

Brasília, DF, Brasil.

Contact: alcantara.daniele@gmail.com

II- Universidade de Brasília, Brasília, DF, Brasil.

Contact: teresacristinasc@gmail.com 


\section{Introdução}

A sociedade atual tem preocupado-se cada vez mais com a segurança pública ou com a sua falta. 0 tema ganha centralidade no debate público como um dos mais graves problemas sociais urbanos no final do século XX e começo do XXI, induzindo a uma redefınição da gestão do espaço urbano, incluindo a gestão da segurança (PONCIONI, 2007). A polícia, em especial, como uma das instituições tradicionais de combate ao crime, tem mostrado-se pouco eficaz para o enfrentamento do tema, configurando o que Lévy (1997) chamou de crise do modelo liberal de organização policial.

Essa crise abriu caminho para que o policial militar passasse a ser um sujeito social de destaque e discussão nos meios de comunicação de forma geral. Nesse sentido, entende-se que é de fundamental importância, nas possíveis intervenções que visam à efetividade do trabalho policial, considerar o exame da formação profissional dos policiais militares. Para tanto, deve-se considerar as concepções dos professores acerca do policial militar como aluno dentro de sua instituição, neste caso, a Polícia Militar do Distrito Federal. É esse o objetivo principal deste trabalho.

A presente pesquisa apresenta um estudo exploratório qualitativo que buscou discutir as concepções de professores que ministram ou ministraram aulas na Academia de Polícia Militar de Brasília (APMB), responsável pela formação dos policiais militares do Distrito Federal, em nível de graduação e pós-graduação lato sensu. Na APMB, pode-se encontrar, ao longo de sua história, professores civis oriundos de instituições conveniadas à PMDF, em específico neste estudo, a Universidade de Brasília e a Universidade Católica, e também professores que são policiais militares.

Uma importante revelação do exame dos cursos de formação profissional de policiais no contexto brasileiro é trazida por Poncioni (2007). Segundo a autora, há tendências semelhantes na formação das instituições de ensino policial, dentre as quais está a presença, mesmo que com ênfases diferenciadas, de um entendimento dominante que tem como preocupação primeira moldar o policial para um comportamento legalista, numa variante burocrático-militar, com forte relevo ao "combate ao crime" (p. 25).

Pensar o policial militar na escola da sua profissão é relevante na medida em que sua qualificação é importante para atender a uma demanda social por melhorias em segurança pública. Quando há uma referência ao professor que convive com alunos policiais militares dentro da APMB neste estudo, a ênfase recai sobre os alunos na PMDF e não fora dela. 0 professor conhece o aluno que está aprendendo a ser policial militar com o primeiro curso de formação, bem como o aluno que está em um curso de aperfeiçoamento ou especialização. 0 sistema de ensino do aluno policial militar possui normas baseadas num regulamento disciplinar que visa à disciplina e ao respeito à hierarquia na PMDF.

\section{A Academia de Polícia Militar de Brasilia e sua estruturação}

A Academia de Polícia Militar de Brasília foi criada pela Lei n. ${ }^{\circ} 7.491$, de 13 de junho de 1986, e implantada pelo Decreto n. ${ }^{\circ} 11.010$, de 12 de fevereiro de 1988, como estabelecimento de ensino e formação superior na PMDF. Atualmente, a Academia de Polícia Militar de Brasília (APMB) é composta pela Escola de Formação de Praças e Escolas de Formação de Oficiais, que, para efeitos legais junto ao Ministério da Educação, passa a ser chamada de Instituto Superior de Ciências Policiais (ISCP). A Escola de Formação de Praças é responsável, como o nome indica, pela formação do quadro de praças, sendo estes soldados, cabos, sargentos e subtenentes. À Escola de Formação de Oficiais cabe a formação do quadro de oficiais, sendo estes cadetes (designação dada ao futuro aspirante a oficial ainda em formação), aspirantes (os quais somente serão declarados oficiais após 
o término do estágio probatório), tenentes, capitães, majores, tenentes-coronéis e coronéis.

As Diretrizes Gerais de Ensino e Instrução (DGEI) foram regulamentadas pela Portaria 426, de 28 de abril de 2004. Conforme a DGEI, o ensino militar terá como finalidade proporcionar aos policiais militares a necessária habilitação para o exercício de cargos e funções previstos no seu quadro de organização, bem como para as atividades do profissional de segurança pública na execução do serviço de polícia ostensiva. Terá ainda o propósito de manter nos seus integrantes a visão da sua inserção no contexto da sociedade do Distrito Federal.

A educação policial militar, segundo a DGEI (2004), dá ênfase especial aos assuntos diretamente relacionados com a atividade-fim, ou seja, o policiamento ostensivo. Ainda de acordo com a DGEI, a instrução deve buscar não somente a fixação de conhecimentos, mas também a educação do homem e a criação de hábitos no profissional, desenvolvendo nele qualidades e aptidões indispensáveis ao bom desempenho de suas missões. Entre as qualidades e aptidões indispensáveis ao bom desempenho da atividade policial, destacam-se: disciplina, coragem, espirito de corpo, resistência física, iniciativa, controle emocional, tato, urbanidade e capacidade de decisão.

A Polícia Militar possui ainda as Normas Gerais para Medida de Aprendizagem (NGMA), texto aprovado pela Portaria 486, de 9 de dezembro de 2005. Essas visam a uniformizar os procedimentos referentes ao processo para a medida da aprendizagem na PMDF, orientando as divisões de ensino dos estabelecimentos de ensino ou seção correspondente das unidades com encargos de ensino, para o cumprimento das normas básicas específicas nos diversos cursos e estágios a funcionarem na corporação.

A matriz curricular da PMDF recentemente passou por modificações no tocante ao trabalho de reformulação dos cursos pela Academia de Polícia Militar de Brasília, de maneira que muitas mudanças estão sendo implementadas quanto à formação dos alunos policiais militares.
As modificações na matriz curricular da PMDF seguiram o referencial da Matriz Curricular Nacional da Secretaria Nacional de Segurança Pública (2009) para ações formativas dos profissionais da área de segurança pública.

A Polícia Militar do Distrito Federal possui, em seu planejamento na área de ensino, o Plano Anual de Ensino (PAE), que tem por objetivo estabelecer e regular o funcionamento dos cursos e estágios na corporação e a previsão da participação de policiais militares da Polícia Militar do Distrito Federal em cursos ou estágios em outras instituições, de acordo com a DGEI de 2004.

Nesse contexto, retoma-se o objeto desta pesquisa, em que a concepção do aluno na APMB depende do processo de ensino e de um conjunto de atividades entre professor e aluno. Percebe-se que os objetivos educacionais expressam propósitos definidos explicitamente e são relativos ao desenvolvimento de qualidades humanas que capacitem o homem para uma condição de transformação social.

\section{O ser professor na PMDF}

0 trabalho do professor consiste numa atividade mediadora entre o indivíduo e o social, ou seja, entre o aluno e as matérias de estudo. Remete-se a Libâneo (1994), para quem o núcleo do trabalho docente está na conciliação entre a atividade do aluno visando à aquisição de conhecimentos e o objeto de conhecimento transmitido pela mediação do professor. Libâneo ainda ressalta que a educação, enquanto atividade intencionalizada, é uma prática social que considera a influência do meio social acerca do desenvolvimento dos indivíduos na sua relação com o meio, "tendo em vista potencializar essa atividade humana para torná-la mais rica, mais eficaz diante das tarefas da práxis social postas num dado sistema de relações sociais" (LIBANEO, 2008, p. 82).

0 conhecimento pedagógico define-se como o saber teórico e conceitual, além do conhecimento dos esquemas práticos do ensino, estratégias pedagógicas, rotinas de funciona- 
mento das intervenções didáticas e os esquemas experienciais dos professores. Refere-se aos conhecimentos institucionais ou escolares que se constituem pelos saberes específicos pertencentes à cultura (BOLZAN, 2002).

A prática profissional do professor, para Schön (2000), é uma ação que exige observação e descrição, implicando múltiplas representações que levam o professor à compreensão das relações existentes no saber escolar. Percebe-se que as concepções de professores sobre sua prática podem ser consideradas como orientações na formação de seus alunos, os quais servem como mediações de cultura, valores e conhecimentos que se transformam na relação em sala:

[...] pode-se dizer que as diferentes articulações [...] entre a prática docente e os saberes constituem mediações e mecanismos que submetem essa prática a saberes que ela não produz nem controla. (TARDIF, 2006, p. 41).

Exercer a docência envolve questões como o relacionamento interpessoal, o compromisso com o outro e a reflexão. Pensar concepções de professores significa uma reflexão sobre os saberes relacionados à prática do docente, aspectos ressaltados por Poncioni (2005), Feiman-Nemser; e Floden (1986), Rangel; Teve (1999), Macedo (2001), Libâneo (1994) e Rebelo (2001). A disciplina existente em sala de aula no tocante à ideia de punir já foi abordada por Foucault (1987), Silva (2011), Amaral (2003), Lima (2002), Costa (2004) e Monjardet (2003).

No caso da educação na Academia de Polícia Militar de Brasília, o presente estudo refere-se ao ensino em nível superior, entendendo docência superior como atitudes desenvolvidas pelos professores orientadas para a preparação de futuros profissionais (ISAIA, 2003). 0 saber do professor engloba: o conhecimento de si mesmo, de suas capacidades, atitudes e valores, o conhecimento do contexto do ensino, relações que o professor estabelece com a administração da instituição escolar, o conhecimento do desenvolvimento do currículo e o conhecimento relativo à aprendizagem, aos alunos, ao ensino e às crenças sobre o ensino. Significa dizer que cada docente apresenta suas concepções de acordo com os conceitos que elabora, com percursos e experiências vivenciadas. 0 que nos permite investigar concepções de professores não é o discurso pronto, mas o modo como essas concepções se manifestam em sua prática efetiva (GARNICA, 2008). A prática do docente no cotidiano com o aluno lhe fornece elementos, os quais se articulam em sua fala a respeito do cotidiano.

\section{Método}

Esta pesquisa tem caráter exploratório, bem como orientação qualitativa, por ser essa uma abordagem possível para uma investigação sobre concepções. 0 estudo exploratório é um meio metodológico de fundamental importância para apresentar a realidade tal como ela é, buscando, a partir do contexto social em que o fenômeno estudado se encontra, compreender o seu significado, percebendo a realidade a partir dos conteúdos da pesquisa em questão (TRIVIÑOS, 2010).

\section{Campo de pesquisa}

No tocante à área de educação na PMDF, tem-se o Departamento de Educação e Cultura (DEC), e, subordinada a ele, está a Diretoria de Formação, em que se situa a Academia de Polícia Militar de Brasília, atualmente conhecida como Instituto Superior de Ciências Policiais. A Academia de Polícia Militar de Brasília (APMB) se divide na Escola de Formação de Praças e Escola de Formação de Oficiais. A pesquisa foi realizada com professores que atuaram junto à Escola de Formação de Praças e Escola de Formação de Ofıciais.

\section{Participantes}

Participaram desta pesquisa voluntariamente dezessete sujeitos, sendo oito professores civis das instituições de ensino superior da 
Universidade de Brasília e da Universidade Católica de Brasília, dentre os vinte professores constantes em documentação na PMDF, e nove professores policiais militares, dentre os vinte e nove relacionados em documentação oficial. Todos ministraram aulas aos policiais militares dentro da PMDF nos cursos de formação de oficiais e formação de praças em nível de graduação, e nos cursos de aperfeiçoamento de oficiais e nos cursos de altos estudos de oficiais em nível de pós-graduação lato sensu. Os professores sujeitos desta pesquisa apresentaram formação acadêmica diversificada, incluindo ciências exatas e humanas.

Os participantes das entrevistas foram identificados atribuindo-se a sigla PC aos professores civis e PPM aos professores policiais militares. Isso contribuiu para, caso fosse necessário, acessar as entrevistas novamente sem identificar os sujeitos.

\section{Instrumento}

Um roteiro de entrevista semiestruturado foi o instrumento deste estudo e se mostrou adequado aos objetivos da pesquisa. Conforme ideias de Alves-Mazzotti (1998), de um modo geral, o roteiro das entrevistas consiste num fraseamento sem uma ordem rigidamente estabelecida para as perguntas, assemelhando-se muito a uma conversa. A pesquisa qualitativa, para Bauer e Gaskell (2004), lida com interpretações da realidade social, utilizando como protótipo a entrevista. 0 roteiro das entrevistas deste estudo teve tópicos que foram seguidos de forma flexível, podendo ser acrescentados outros se necessário para a compreensão da fala dos sujeitos.

\section{Análise de dados}

As entrevistas foram analisadas tendo como referência a técnica de análise de conteúdo de Bardin (2011), que é um conjunto de técnicas de análise de comunicações que utiliza procedimentos sistemáticos e objetivos de descrição do conteúdo das mensagens. A categorização, que no caso desta pesquisa foi feita por tema, é um processo que faz parte da análise de conteúdo e que permite uma melhor manipulação do material que foi analisado.

A análise de conteúdo neste estudo significa um conjunto de criação de categorias a partir das falas dos entrevistados, o qual visa, por procedimentos de descrição do conteúdo das mensagens, a obter indicadores qualitativos que permitam o conhecimento relativo às concepções de professores acerca do aluno policial militar da APMB. Após o processo de categorização e agrupamento, foram encontradas cinco categorias que serão discutidas, sendo estas: imagem do aluno policial, relacionamento interpessoal, consciência do sistema disciplinar, ensino na PMDF e vínculo com a prática policial militar.

\section{Resultado e discussão das categorias}

\section{Imagem do aluno policial militar}

A imagem do aluno policial militar para os professores está constantemente associada a alguém disciplinado, considerando a vivência que se estabelece em sala e o tipo de comportamento norteado por princípios de disciplina. Para os professores, os alunos evidenciam, na rotina em sala, a disciplina e a dedicação às aulas:

PC- [...] eles de fato são disciplinados durantes as aulas e são dedicados ao extremo às matérias... Ah... esta é a imagem que tenho; isto fica muito claro desde o primeiro momento que entro em sala.

Os professores policiais militares enfatizam que os alunos estão num sistema em que a imagem deve obrigatoriamente estar conectada à disciplina:

PPM- [...] quando eles entram aqui, e seja em qualquer curso, têm que ter um comportamento adequado: a sua 
imagem vai estar arraigada ao tipo de comportamento que se tem... Assim, além do mais, a primeira coisa de qualquer curso daqui é a disciplina; a imagem deles é de disciplina, não dá para ser diferente, sabe.

Percebe-se que, tanto para os professores policiais militares quanto para os professores civis, o aluno policial militar é disciplinado, e ambos reconhecem que a disciplina do aluno está ligada à legislação à qual está submetido.

Sobre o aspecto disciplinar, Poncioni (2005) observa que, dentro da organização, principalmente no período de treinamento, transmite-se a ideia do trabalho policial com ênfase na importância de sua adesão às regras e procedimentos da organização para o controle do crime nos limites da lei, o que garante a transmissão da disciplina aos alunos policiais e caracteriza a dinâmica da instituição de ensino (FEIMAN-NEMSER; FLODEN, 1986).

Segundo os professores, os alunos policiais militares sabem que ser policial não é apenas uma profissão, mas implica mudanças na sua imagem - incluindo os comportamentos -, na fala, nas roupas e no círculo de amizades.

Essa percepção do aluno ocorre não apenas durante todo o período de formação policial militar mas também ao longo da sua carreira nos demais cursos da PMDF. Há, de fato, por parte dos professores, uma incorporação da imagem do aluno oriunda do sistema de aprendizagem da APMB e de costumes da profissão, seja por meio de códigos comuns construídos ou pela própria história da PMDF. Todos esses aspectos se conectam à imagem que os professores têm do aluno em sala.

É necessário que o discente observe a si mesmo e seu grupo de trabalho em circunstâncias práticas diversificadas, experimentando a reflexão e a análise entre a própria percepção e a dos professores a seu respeito, o que, de acordo com Perrenoud (2002), ampara o docente na análise de valores, de atitudes e de papéis sociais, além de permitir a explicação e revisão, oferecendo ao aluno a possibilidade de tomar consciência de suas necessidades e das motivações de suas ações e de, a partir daí, idealizar um projeto pessoal de formação, transitando de uma simples aquisição de saber-fazer para uma formação que leve a uma identidade profissional.

Tanto os professores civis quanto os professores policiais militares confırmam que o aluno demonstra atenção ao conhecimento proposto nas aulas. Esse aspecto pode ser percebido pela dedicação dispensada a cada momento que o docente introduz um novo assunto. Para os professores, o interesse em aprender alcança um ponto importante, em que novamente esse aluno busca a aplicabilidade prática do assunto que está sendo exposto durante as aulas.

Rangel e Teve (1999) apontam que a relação teoria-prática é relevante para o alcance da multidimensionalidade do processo de ensino e aprendizagem, considerando-se que as referências teóricas são necessárias à consciência do significado das ações. Essas ideias estão estabelecidas na Matriz Curricular Nacional (2009), em que os conteúdos não devem ser considerados um fim em si mesmo, mas ferramentas que possibilitem a reflexão intencional sobre a prática do profissional da área de segurança pública, bem como acerca das maneiras possíveis de intervenção na realidade.

Embora os professores civis tenham a imagem de que o respeito do aluno policial militar é maior do que o respeito dos demais alunos que não sejam militares, percebe-se que essa diferenciação ocorre de forma menos marcante para o professor policial militar, que reconhece o aluno policial militar como um indivíduo treinado que não deve exceder os limites que são estabelecidos para suas ações.

De maneira geral, os professores reconhecem o aluno policial militar como alguém disciplinado, respeitador, pontual, com elevado nível intelectual, que tem interesse em aprender e sempre procura relacionar o conteúdo das matérias a situações práticas da profıssão. Além da imagem do aluno policial militar, os professores apresentaram concepções 
de suas relações com esses alunos. Tal aspecto será abordado no seguinte item.

\section{Relacionamento interpessoal}

Os professores relatam que o relacionamento que possuem com os alunos é positivo, havendo momentos de descontração, respeito, amizade, união e espírito de colaboração. No caso dos professores policiais militares, esse tipo de comportamento dos alunos com o professor já é esperado, pois, por serem todos policiais militares, conhecem as normas do ensino na PMDF e sabem como a relação professor-aluno deve ser:

PPM- [...] desde cedo, estimula-se a camaradagem entre todos. Precisamos de uma relação saudável... Nossa profissão já é tão tensa às vezes, que temos que ter com o aluno uma relação amistosa desde a escola, isto é sem dúvida.

Os professores reconhecem que um bom relacionamento professor-aluno, conforme assinala Macedo (2001), apresenta-se como importante quesito utilizado pelo professor em sua prática pedagógica. Cabe ao docente agir com competência, ou seja, tomar decisões, escolher a melhor forma de propor debates, avaliar as melhores referências ou valores, saber correr riscos e fazer o melhor uso dos conhecimentos ou informações como importantes elementos do processo de ensino-aprendizagem.

Tanto professores civis quanto professores policiais militares demonstram uma grande exigência para que o aluno aprenda, e há um comprometimento por parte dos docentes para que esse aluno realmente absorva o conhecimento proposto em cada aula.

Contudo, o professor policial militar exige explicitamente que o aluno aprenda e preste atenção à aula, pois a qualificação do aluno é importante para que ele seja um policial preparado para exercer a profissão, não havendo, por parte do professor policial militar, difıculdade em mostrar a função de um determinado conhecimento. No caso dos professores civis, os mesmos relatam que tiveram dificuldades em transmitir a importância de uma determinada matéria, por serem estas da grade civil:

PC- [...] eles realmente aprendem muita coisa, e preciso mostrar a função de cada conhecimento, da importância das discussões para a profissão deles; senão, eles ficam mais resistentes a participarem.

PPM- [...] eu sinto muito, mas eles precisam aprender. 0 policial não pode ter muitas dúvidas em relação a sua conduta. Por isso, na hora das aulas, eu cobro muito deles, pergunto para todos, os coloco em situações de conflito... Há uma relação de cobrança, sim, e eles sabem a importância de dominar uma matéria.

Os exercícios que fazem parte da rotina do aluno policial militar são atividades participativas que não devem causar estranhamento, segundo os professores policiais militares, pois os alunos, ao ingressarem nos cursos, sabem que terão que se envolver em diversos exercícios. Quanto à participação em sala de aula, fica evidenciado que os docentes, mais destacadamente os professores policiais militares, reconhecem que, no início dos cursos, os alunos são mais reservados e que logo passam a participar efetivamente das aulas.

Os professores ressaltam que a participação em sala fortalece a relação entre professor e aluno nas atividades dos cursos. 0 aluno tem a possibilidade de desenvolver, além da parte técnica, a percepção de união e camaradagem. Percebe-se que a disciplina é introjetada no relacionamento em sala de aula, pois a relação professor-aluno é mediada por horários estabelecidos e cumpridos rigorosamente; além disso, os alunos possuem um cuidado especial com o modo como se apresentam aos professores. 
A relação entre professores e alunos policiais militares envolve um conjunto específico de conhecimentos teóricos referentes à vida na PMDF, desenvolvidos e aplicados na APMB. Nesse ponto, os professores foram levados a refletir sobre o tipo de relacionamento que têm com os alunos da pesquisa, conforme verificado até aquele momento.

A relação em sala é um aspecto fundamental da organização didática, mas não é o único fator determinante da estruturação do ensino e da percepção dos alunos, razão pela qual ela precisa ser estudada em conjunto com outros fatores, principalmente a forma de aula (LIBÂNEO, 1994).

A ausência de reflexão dos professores acerca de seus alunos pode ocasionar atos fundados em posturas adotadas como válidas e verdadeiras meramente por refletirem uma posição aceita. Mas precisa-se pensar em atos que possam existir apenas por serem coniventes com um regime de ensino que conduz o aluno à consciência constante do sistema disciplinar, conforme será visto na categoria a seguir.

\section{Consciência do sistema disciplinar}

Foi evidenciado que os professores percebem os alunos policiais militares como aqueles que têm consciência do sistema disciplinar, em que a formação é pautada na hierarquia e na disciplina e estas são ligadas à punição. Principalmente nas aulas, existem regras a ser observadas para garantir o andamento do ensino. A punição está relacionada ao medo que os alunos têm da mesma, pois esta pode ser aplicada de diversas formas.

0 aluno policial militar, segundo os professores, conhece seu tempo e seu espaço dentro dos cursos na APMB, pois o sistema no qual está inserido é claro no tocante aos comportamentos aceitáveis e esperados. Para a $\mathrm{APMB}$, é importante não apenas que o aluno tenha consciência das suas ações mas também que obedeça ao modo pré-determinado e descrito nos regulamentos e legislações da PMDF.

Pelo que foi apreendido nas entrevistas, o aluno policial militar tem consciência do lugar que ocupa na hierarquia e do fato de que aquele que possui maior grau hierárquico deve ser chamado de senhor. No caso dos professores civis, todos são chamados de senhor; já no caso dos professores policiais militares, a hierarquia funcional é seguida em sala. É um primeiro aspecto de introjeção da cultura militar nos cursos de formação e nos contatos entre docentes e alunos:

PC- [...] o que observo é uma disciplina consciente: eles sabem seus limites, eles sabem até onde podem ir e temem ir além daquilo que é permitido.

PPM- [...] Ah sim... o aluno tem disciplina consciente, ele sabe que a dedicação é importante, seguir as normas daqui também é fundamental. Um aluno daqui sempre vai ser disciplinado.

Segundo Foucault (1987), a arte de punir, no regime do poder disciplinar, não tem como fim a expiação e a repressão, mas sim o funcionamento de operações que relacionam atos, desempenhos, comportamentos singulares num campo de comparação e, ao mesmo tempo, num espaço de diferenciação. Entende-se que a prática de punir funciona como natural, necessária e, logo, legítima no regime de poder disciplinar.

0 modo como os professores policiais militares percebem o aluno policial militar no que se refere ao sistema disciplinar está ligado à formação do próprio professor e a suas experiências na APMB. 0 aluno policial militar é visto como aquele que deve buscar a perfeição em todas as suas atividades, sendo que essa busca é mediada pelas punições do sistema educacional.

Os comportamentos que são reprováveis por parte dos professores quase sempre se resumem ao descumprimento de prazo de uma ordem superior qualquer ou a alguma 
falta de asseio com equipamentos e uniformes ou mesmo a alguma conduta considerada inadequada, o que, no sistema disciplinar, é comumente chamado de alterações.

Segundo Silva (2011), alterações podem ser definidas, em linhas gerais, como coisas ou condutas fora de ordem ou de lugar que, ao serem observadas e informadas ao escalão superior, iniciam um processo de incriminação. Nesse sentido,

[...] alterações são consideradas condutas desviantes dentro do sistema representacional nativo e, quando não são justificadas, arquivadas ou anuladas pelo corpo de alunos, resultam em punições de aluno ou, se consideradas mais graves, em punições de regulamento disciplinar. (SILVA, 2011, p. 178).

Para os professores civis, o processo de conscientização do sistema disciplinar deve seguir um planejamento que permita ao aluno policial militar conhecer os motivos do que está sendo transmitido, como a importância de saber lidar com as atribuições de maneira profissional. Os docentes apontam que o aluno tenta controlar suas ações para se ver livre de punições.

\section{Ensino na APMB}

$\mathrm{Na}$ categoria que trata do ensino na APMB, os docentes ressaltam o tipo de ensino que o aluno policial militar recebe. Para os professores civis, há uma distinção entre as matérias que são civis e aquelas que tratam de conhecimentos inerentes ao militarismo e à profissão de policial militar. Os professores policiais militares não abordam esse assunto diretamente:

PC- [...] nós recebemos as matérias entendendo o que é do corpo militar e do corpo civil, para organizar o conteúdo que eu ia passar e não sobrepor conteúdos. Logo, reconhecemos que precisamos fazer uma relação dos conteúdos com a profissão de policial. Mas os alunos têm matérias específicas do meio militar, muito específicas e, pelo que vi, são coisas que eles precisam saber muito bem.

No ensino policial militar, os professores civis percebem, em relação aos alunos, que sua formação possui como marca a separação entre o ensino civil e o ensino militar. Essas são concepções por meio das quais os professores civis observam que o aluno policial militar tem incorporada à sua formação a separação de dois mundos: o civil e o militar.

Os professores civis sugerem que a APMB inclua em seus currículos mais matérias voltadas para o desenvolvimento humano, com as quais o aluno possa conhecer determinados comportamentos humanos e possíveis justificativas para eles. Também destacam que é necessário contextualizar as matérias civis para o ensino do policial militar, ou seja, precisa-se mostrar que um dado conhecimento é útil para a atividade prática do policial militar.

Os professores policiais militares também expressam, embora com menos destaque, que matérias ligadas às questões éticas e de diversidade cultural devem ser valorizadas, reconhecendo o papel central das dimensões éticas e culturais na formação do indivíduo, enquanto ser moral e cidadão. Libâneo (1994) esclarece que, para que o docente atinja os objetivos de uma disciplina, alguns pontos devem ser observados. 0 professor deve explicar a matéria, trazer dos alunos conhecimentos que já dominam, saber detectar o nível de capacidade dos alunos, não do aluno ideal, mas dos alunos concretos que ele tem à sua frente.

Há ainda a predominância de uma formação do aluno policial militar voltada para as leis em termos de conteúdo. Pode-se pensar numa predominância do "modelo policial profissional tradicional” (PONCIONI, 2005). Entende-se que o conteúdo da formação do futuro policial encontra-se pautado numa concepção do trabalho que enfatiza o aspecto legalista da profissão dentro da cultura policial, da filosofia de trabalho, da 
política administrativa, do treinamento e das estratégias policiais.

Os professores destacam que o aluno policial militar está dentro de uma formação rígida e meritocrática, ou seja, em que o mérito de cada aluno é vinculado às notas e à disciplina que apresenta durante os cursos.

0 sistema competitivo do ensino na PMDF é visto como algo negativo pelos professores civis, enquanto os professores policiais militares não abordam o tema com destaque. Os docentes civis acham que os ensinamentos seriam mais proveitosos se o sistema da PMDF fosse menos competitivo, tendo em vista que os alunos se preocupam muito com as notas, o que torna a aprendizagem fonte de ansiedade.

Os professores policiais militares e civis percebem que as notas são importantes na carreira do policial militar. A classificação do aluno policial militar nos cursos de formação é que define sua antiguidade na PMDF. Isso significa dizer que a nota final do curso de formação define a ordem de promoções até o posto/graduação no qual o critério de antiguidade for considerado mais importante. A nota mais alta no primeiro curso de formação na PMDF define aspectos da vida profissional do aluno, tais como o local onde vai trabalhar e a prioridade nas promoções internas.

\section{Vínculo com a prática policial militar}

De forma geral, os professores percebem que a formação do aluno policial militar inclui treinamentos ligados à prática policial. Amaral (2003) assinala que, com efeito, a atividade daquele que lida com a segurança pública é deveras importante, mas se exigem sempre o bom senso e o equilíbrio nas ações, até porque estas se refletem como um todo na sociedade. Daí o motivo pelo qual o:

[...] preparo emocional (inclusive sua manutenção constante) e o preparo técnico (jurídico sobretudo, porque a operacionalidade para a polícia pressupõe, acima de tudo, embasamento jurídico-legal) são lados da mesma moeda. (AMARAL, 2003, p. 56).

É comum, quando se questiona o desempenho dos policiais, relacionar o mau desempenho com despreparo e atribuir o despreparo à má formação. Embora, em muitos casos, a relação seja procedente, como nos casos de mau uso da arma de fogo, é preciso indagar se realmente o mau desempenho em geral é resultado de despreparo ou se não decorre de fatores de outra ordem (LIMA, 2002), dentre os quais podem estar problemas pessoais e estresse:

PC- [...] o treinamento de policiais deve ser constante, deve haver uma formação contínua... Sem dúvida, o treinamento promove o equilíbrio nas decisões na atividade propriamente de segurança.

PPM- [...] cuidamos do bom desempenho do aluno porque este direciona sua prática policial. Daí a necessidade da repetição em algumas aulas... Mas tudo depende de controle emocional.

Os professores possuem a concepção de um aluno que deve ter capacidade técnica para atuar como policial militar. Destacam a importância do treino técnico que permita ao aluno aprender a lidar com multidões, imobilizando as pessoas sem lesioná-las. Daí a preocupação dos docentes com a qualificação, a fim de que o policial militar não atue de forma abusiva, tenha consciência do que faz e use a arma de fogo somente quando realmente se fizer necessário. Observa-se que os docentes enfatizam um aluno que deve ser dotado de conhecimentos que lhe permitam atuar na rua de diversas formas, sendo a prevenção ao crime a principal delas.

Os professores policiais militares destacam que, por fazerem parte da PMDF, conhecem os alunos ou irão, em algum momento, trabalhar 
com eles. 0 papel do professor é, então, importante, não como figura central, mas como coordenador do processo educativo, o qual, usando de sua autoridade democrática, cria, em conjunto com alunos, um espaço pedagógico interessante, estimulante e desafiador, para que nele ocorra a construção de um conhecimento científico significativo (REBELO, 2001).

Para os docentes, o aluno policial militar deve ser treinado para saber agir em situações reais com competência, aplicando a técnica policial para salvar vidas, destacando a especialização dos alunos em treinamentos de tiros que visem a cessar a ação de um possível agressor e a não matá-lo.

Os professores policiais militares enfatizam que o aluno vai pôr em prática seus conhecimentos quando sair para trabalhar e atuar já formado, sendo importante o treinamento técnico constante. Entendem como treinamento técnico aulas de tiro, defesa pessoal, negociação e policiamento comunitário. Estes foram os mais citados pelos docentes.

Os professores civis preocupam-se com uma capacitação do aluno voltada para o uso da força em casos extremos, em que ela realmente se faça necessária. Há uma preocupação para que o aluno policial aprenda a não ser violento.

Os docentes civis reconhecem que os conhecimentos da Academia de Polícia devem ser incorporados ao trabalho dos policiais militares. Segundo Costa (2003), para tal, os conhecimentos devem ser transformados em técnicas policiais, manuais de treinamento e códigos de conduta. Isso permite que as condutas individuais sejam avaliadas não só com relação à sua legalidade mas também do ponto de vista profissional. Policial qualificado é aquele que detém um conhecimento profundo das regras legais e dos procedimentos operacionais (MONJARDET, 2003). 0 aluno policial militar é percebido como alguém submetido a um treino técnico.

Os professores reconhecem que há um esforço para que o aluno policial militar aplique as técnicas ensinadas para salvar uma vida. 0 tiro aparece como tema recorrente nas falas desses docentes e há uma preocupação em buscar a menor letalidade na ação policial. 0 aluno policial militar é visto como um profissional treinado para preservar a segurança de todos e não para matar na rua de forma descontrolada.

\section{Considerações finais}

Este trabalho apresenta um caminho percorrido que teve por objetivo conhecer e analisar as concepções de professores civis e professores policiais militares acerca do aluno policial militar da Academia de Polícia Militar de Brasília. A partir do presente estudo, foi possivel conhecer concepções de professores acerca desse aluno. Percebe-se que o aluno policial militar é visto pelos professores a partir da experiência e da formação de cada um, ou seja, cada docente tem no seu olhar as marcas da sua história na educação e na APMB.

As concepções desses professores surgiram num processo de interação e comunicação em sala. Por isso, são consideradas relacionadas à realidade, sendo construídas e reconstruídas a partir das práticas cotidianas. Estas são concebidas neste estudo como reflexos de expressões dos sujeitos da pesquisa. 0 interesse em ouvir os professores justifica-se por serem considerados atores importantes no processo de ensino e aprendizagem na formação de policiais militares.

A pesquisa revela que os professores, sejam os civis ou os militares, têm ciência dos limites impostos ao aluno policial militar diante de uma formação baseada na hierarquia e disciplina.

Nota-se o papel fundamental do tipo de relacionamento professor-aluno na construção de concepções de professores, já que, por meio dos diálogos cotidianos em sala de aula, as informações são repassadas e invariavelmente ligadas entre si no meio em que são produzidas. Os professores civis e professores policiais militares possuem concepções semelhantes em 
relação ao aluno policial militar. Ambos apontam um aluno que é levado a agir de acordo com normas e dentro de valores institucionais.

\section{Referências}

ALVES-MAZZOTTI, Alda Judith. Representações da identidade docente: uma contribuiç̧ão para a formulação de políticas. Ensaio: Avaliação e Políticas Públicas em Educação. Rio de Janeiro, v. 15, n. 57, p. 579-594, out./dez. 2007. Disponível em: < http://www.scielo.br/pdf/ensaio/v15n57/a08v5715.pdf > . Acesso em: nov. 2013.

AMARAL, Luiz Otávio de Oliveira. Direito e segurança pública: a juricidade operacional da polícia. Brasília, DF: Consulex, 2003. BARDIN, Laurence. Análise de conteúdo. Porto: Edições 70, 2011.

BAUER, Martin; GASKELL, George (Orgs.). Pesquisa qualitativa com texto, imagem e som: um manual prático. Petrópolis: Vozes, 2008. BOLZAN, Dóris Pires Vargas. Formação de professores: compartilhando e reconstruindo conhecimentos. Porto Alegre: Mediação, 2002. COSTA, Arthur Trindade Maranhão. Entre a lei e a ordem: violência e reforma nas polícias do Rio de Janeiro e Nova York. Rio de Janeiro: FGV, 2004.

DGEI - Diretrizes Gerais de Ensino e Instrução: Portaria PMDF nº 416 de 28 de Abril de 2004. Brasília, DF: PMDF, 2004.

FEIMAN-NEMSER, Sharon; FLODEN, Robert. The cultures of teaching. In: WITTROCK, Merlin C. Handbook of research on teaching. New York: Macmillan, 1986. p. 505-526.

FOUCAULT, Michel. Vigiar e punir: nascimento da prisão. Petrópolis: Vozes, 1987.

GARNICA, Antonio Vicente Marafioti. Um ensaio sobre as concepções de professores de matemática: possibilidades metodológicas e um exercício de pesquisa. Educação e Pesquisa, São Paulo, v. 34, n. 3, p. 495-510, set./dez. 2008.

ISAIA, Silvia Maria de Aguiar. Professores de licenciatura: concepções de docência. In: MOROSINI, Marilia Costa (Org.). Enciclopédia de pedagogia universitária. Porto Alegre: FAPERGS/RIES, 2003. p. 263-277.

LÉVY, René. A crise do sistema policial francês hoje: da inserção local aos riscos europeus. Tempo Social: Revista de Sociologia da USP, São Paulo, v. 9, n. 1, p. 53-77, maio 1997.

LIBÂNEO, José Carlos. Didática. São Paulo: Cortez, 1994.

LIBÂNEO, José Carlos. Pedagogia e pedagogos para quê? São Paulo: Cortez, 2008.

LIMA, Roberto Kant de. Políticas públicas de defesa social e a formação de policiais. In: ZAVERUCHA, Jorge; BARROS, Maria do Rosário N. (Orgs.). Políticas de segurança pública: dimensão da formação e impactos sociais. Recife: Massangana, 2002.

MACEDO, Lino de. Ensinar: agir na urgência, decidir na incerteza, de Philippe Perrenoud. Revista Pátio Aqui se Aprende, Porto Alegre, v. 5, n. 1, 2001.

MONJARDET, Dominique. 0 que faz a polícia: sociologia da força pública. Tradução Mary Amazonas Leite de Barros. São Paulo: Edusp, 2003.

NORMAS gerais para medida da aprendizagem: Portaria nº 486 de 09 de dezembro de 2005. Brasília, DF: PMDF, 2005.

PERRENOUD, Philippe. A prática reflexiva no ofício de professor: profissionalização e razão pedagógica. Porto Alegre: Artmed, 2002.

PONCIONI, Paula. 0 modelo policial profissional e a formação profissional do futuro policial nas academias de polícia do Estado do Rio de Janeiro. Sociedade e Estado, Brasília, DF, v. 20, n. 3, p. 585-610, set./dez. 2005.

PONCIONI, Paula. Tendências e desafios na formação profissional do policial no Brasil. Revista Brasileira de Segurança Pública, São Paulo. v. 1, n.1, p. 22-31, 2007. 
RANGEL, Mary; TEVE, Nilda. (Orgs.). Representações sociais e educação: temas e enfoques contemporâneos de pesquisa. Campinas: Papirus, 1999.

REBELO, Rosana Aparecida Argento. 0 diálogo como prática pedagógica contribuindo para a superação da indisciplina escolar. In: FREIRE, Ana Maria Araújo (Org.). A pedagogia da libertação em Paulo Freire. São Paulo: Unesp, 2001. p. 243-250.

SCHÖN, Donald. Educando o profissional reflexivo: um novo design para o ensino e a aprendizagem. Porto Alegre: Artmed, 2000.

SECRETARIA NACIONAL DE SEGURANÇA PÚBLICA. Matriz curricular nacional. Brasília, DF: Ministério da Justiça, 2009.

SILVA, Robson Rodrigues. Entre a caserna e a rua: 0 dilema do "pato": Uma análise antropológica da instituição policial militar a partir da Academia de Polícia Militar Dom João VI. Rio de Janeiro: UFF, 2011.

TARDIF, Maurice. Saberes docentes e formação profissional. Petrópolis: Vozes, 2006.

TRIVIÑOS, Augusto Nibaldo Silva. Introdução à pesquisa em ciências sociais: a pesquisa qualitativa em educação. 1. ed. São Paulo: Atlas, 2010.

Daniele Alcântara Nascimento é mestre em educação pela Universidade de Brasília, doutoranda em sociologia na área de violência, segurança e conflitualidades pela Universidade de Brasília, membro do Grupo de Estudos e Pesquisa em Psicologia e Educação (GRUPPE) e professora do Instituto Superior de Ciências Policiais.

Teresa Cristina Siqueira Cerqueira é doutora em educação, na área de psicologia educacional pela Universidade Estadual de Campinas, mestre em psicologia na área de psicologia social e da personalidade pela Universidade de Brasília e professora da Faculdade de Educação da Universidade de Brasília, pesquisadora do CNPq e coordenadora do Grupo de Estudos e Pesquisa em Psicologia e Educação (GRUPPE). 